\title{
The Development of Services in Customer Relationship Management (CRM) Environment from 'Technology' Perspective
}

\author{
Gaurav K. Agrawal ${ }^{1}$, Daniel Berg ${ }^{2}$ \\ ${ }^{1}$ Decision Sciences and Engineering Systems, Rensselaer Polytechnic Institute, Troy, USA; ${ }^{2}$ Decision Sciences and Engineering Systems, Rensselaer \\ Polytechnic Institute, Troy, USA. \\ Email: gkagrawal@engineer.com, bergd@rpi.edu
}

Received May 15, 2009; revised July 2, 2009; accepted August 21, 2009.

\begin{abstract}
The service sector is receiving much deserved attention resulting from its inevitable role in a country's economic development. Despite all the efforts gaps such as the relationship between technological advances and service development are yet to be revealed from the perspective of new applications that organizations want to develop and implement. This paper explores opportunities using a comprehensive model (and CRM, as an example) that can be used to extend the research relating service development to the technology development aspects of the market.
\end{abstract}

Keywords: Service Systems, Service Hierarchy, Customer Relationship Management, Service Development, Technology Complexity

\section{Introduction}

Presently, extremely competitive and globalized markets demand economic globalization as a 'must do' activity for the competitors to maintain their niche in the (service) market. Technology development is seen as a solution, allowing organizations to enhance their service portfolios using latest technological advancements. Also, new technology development triggers the service development process to be more customer intensive with customized service offerings. With the shorter maturity times of (different services and hence) the service organizations [1], it became evident for businesses to pursue the technology development and its implementation aspects at a faster pace. It is established that 'technology' plays an inevitable role in the service development process [2-4].

With the increasingly changing perception (of customers) and fierce competition (among business organizations) at the international level, organizations lean towards using customer relationship management (CRM) like approaches. CRM is known to be a strategic approach where organizations implement new processes enabling them to create long term profitable relationship with their customers. The use of CRM approach in different industrial sectors (manufacturing, services, construction, extraction, and mining) requires associated organizations to be technology compatible to implement them. This paper discusses the need and impact of implementing different technologies (with varying levels of complexities) in the course of developing (new) services from the customer relationship management perspective. CRM is proven to be helpful in organizing and analyzing activities (e.g., marketing, sales, customer services, etc.) in an organization to keep the overall organizational efforts useful to both the customers' and the organizations' growth and development.

A systems level approach is used, in this paper, to identify the level of technical complexity that needs to be employed in developing and operating different services. A Service System is defined as a collection of different (service-sub) systems, and their placement with well defined roles and responsibilities. The customer relationship management concept (at large), its applicability and relationship to service development processes and levels of technology being used to develop them is discussed as well.

\section{Service Systems and CRM}

In simple terms a system can be a group of several interacting elements consisting input parameters, a process to manipulate them and output(s). A service system on the other hand is said to have - customers, a physical or vir- 
tual facility to house the required hardware and/or infrastructure, and service providers. Services can be distinguished from other activities based on their specific characteristics, a.k.a. CHIPS which represent Coproduction, Heterogeneity, Intangibility, Perishability and Simultaneity [5]. Similarly, the concept of service package consisting Delivery, Infrastructure and Product a.k.a. DIP can be used in defining the service systems [5].

In case of a simple service system, e.g. a restaurant (as shown in Figure 1), it is observed that to offer end services to their immediate customers, it would need to use several other services. This would require the main service system (restaurant in this example) to interact with other service (sub) systems, e.g., transportation services, banking services, insurance services, credit card services, recreational services, etc. The visibility of systems (including its sub-systems) varies based on their access to customers and their placement in the system.

A closer look on such a system clarifies that all the sub-systems (e.g. credit card services, transportation services, insurance services, etc.) providing their services to a master service provider (restaurant in above example), can actually be the master service providers to other service (sub) systems. While analyzing an end service provider, it is clearly observable that all the sub-systems can be given a specific role and placement in its service system hierarchy. While on a global level all the service systems are expected to have some (moderate to extensive) level of interaction with other systems in the hierarchy subject to their role and placement in it (as shown in Figure 2).

Every member in a service system hierarchy (i.e. a service sub-system) consists of their own target customers, business strategy, development \& expansion plans, software and hardware requirements, infrastructural needs, and marketing policies. Such a diverse set of differentiating factors among service sub-systems makes it crucial to study the primary and secondary effects of them on their customers [6] and observe their relationship with each other. The interactive relationship amongst the systems in whole can be said to have a significant impact on setting the market trends. The change in (sub) systems' operating and developing strategies creates a dynamic impact on all other (sub) systems, due to their close and regular interaction needs.

The role of customers in a business is as important as the business itself. All businesses (including manufacturing, services, agriculture, mining and construction) operate to fulfill their customers' direct or indirect requirements in a best way suitable for their mutual development. Services, although, have the unique characteristics of having the mandatory presence of customers as the co-producers [7]. In the midst of fast paced, globally competitive environment and continually growing need

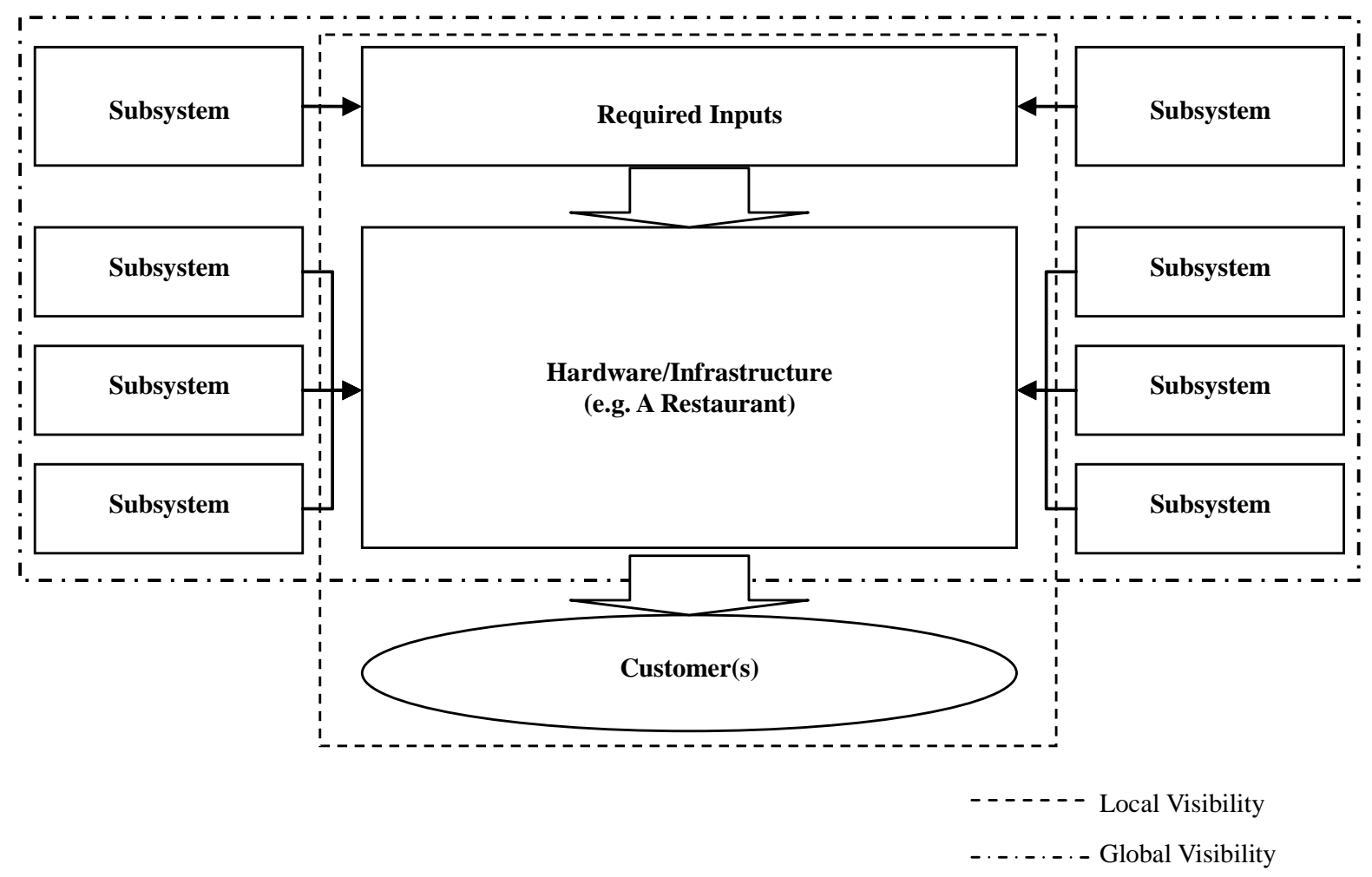

Figure 1. Example of a complete service system, using subsystem approach 


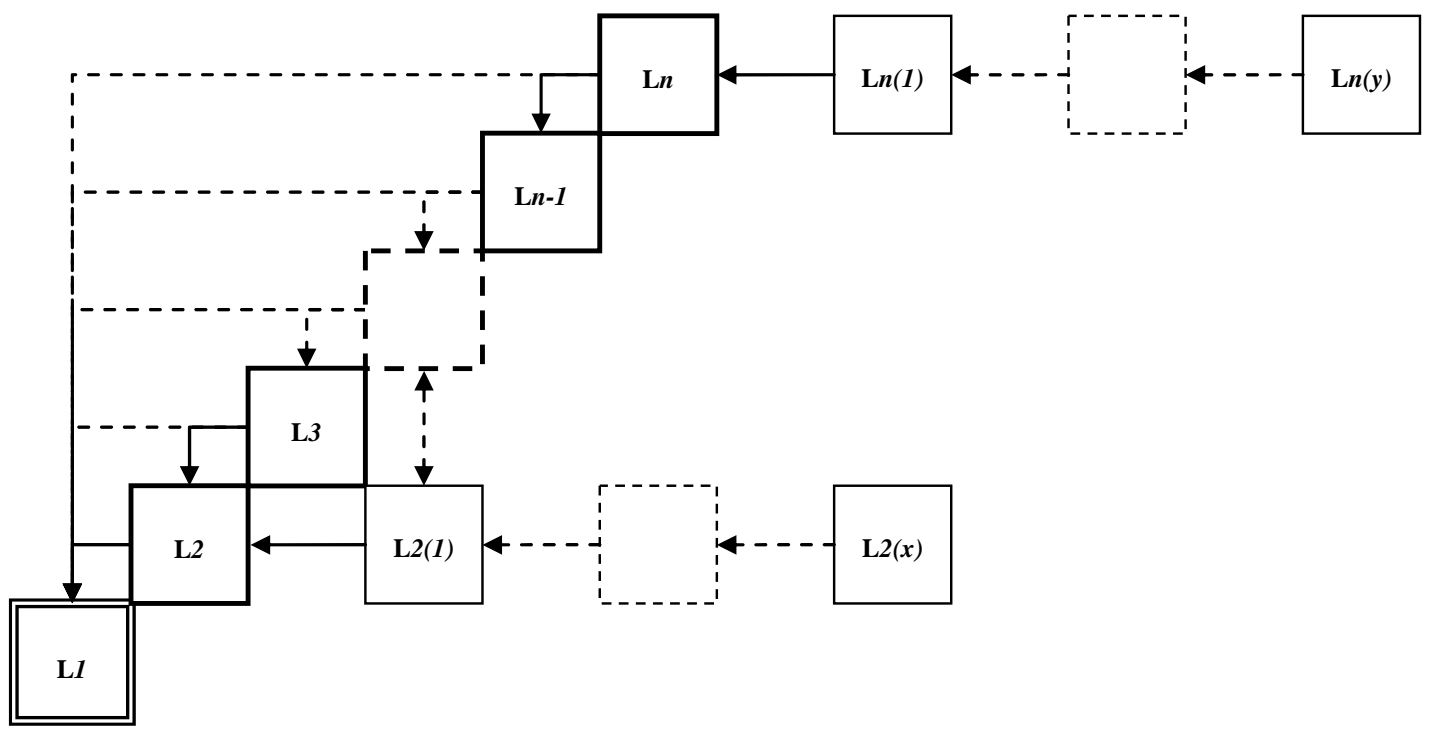

Figure 2. Master service system (L1) with its first and second level subsystems

of economic globalization, it has become evident for the businesses to not only look for new market segments to expand but also work harder to retain their existing customer base. Different organizations/businesses choose a variety of strategies to earn the loyalty of their customers. This includes examples such as sales follow ups, free upgrades, quick complaint responses, free home deliveries, holiday packages, personalized call center responses, etc. Based on the size, need and type of businesses, organizations opt either for a single or a combination of several strategies to expand their customer base while serving their existing customers within their best abilities. This whole process is named as the "Customer Relationship Management” or CRM. Payne and Frow [8] defined CRM as -

"CRM is a strategic approach that is concerned with creating improved shareholder value through the development of appropriate relationships with key customers and customer segments. CRM unites the potential of relationship marketing strategies and IT to create profitable, long-term relationships with customers and other key stakeholders. CRM provides enhanced opportunities to use data and information to both understand customers and cocreate value with them. This required a cross-functional integration of processes, people, operations, and marketing capabilities that is enabled through information, technology, and applications [8]."

Several organizations are dedicating their resources to deliver an optimized (software) system to serve the CRM needs of different organizations. Microsoft ${ }^{\circledR}$, ORACLE ${ }^{\circledR}$, SAP, Salesforce.com ${ }^{\circledR}$ are some of the major players in the CRM arena. Aside pure service providing organizations, other industrial sectors receive a large portion of their revenues from the service activities they offer.
Some good examples in the manufacturing sector are GM, IBM, etc., where a large portion of their annual revenue comes from their service counterparts. In a similar fashion other sectors (i.e. mining, agriculture, and construction) though may not qualify as pure service organizations but do have a large sum of their revenues coming from the services they offer. Embedded relationships, like these, between non-service organizations and their embodied service providing networks make the requirements of CRM like interfaces more crucial and hard to ignore to keep them operational.

\section{Technology, Business Process Outsourcing and CRM in Services}

The concept of CRM is not as new as its accepted need and demand for different application packages in the market (in last decade or so). The concept of building customer relationships is as old as any business in the industrial world. With the increasing competition among different business (organizations) types, technology used, originating subcontinents, etc. their survival becomes highly dependent on their capabilities to sustain their competitive positioning and customer base. Introduction of new technologies (e.g. internet and IT based tools) not only reduced the distance among customers and business owners but also brought the opportunities of sub contracting the business functions overseas with much reduced costs and enhanced effectiveness. The concept of Business Process Outsourcing (BPO) had emerged in the past decade to provide an edge to different (mainly US based) business owners in terms of gaining the strategic advantage over their non US counterparts. The concept of BPO was added to the multidimensional scenario of the industrial world as the low cost solution of mainly its 
information technology (IT) and finance operational needs. BPO did not only introduce the low cost IT and Finance business solutions to the corporate world but also paved the way for the global strategic management of technological innovation. With the intercontinental business ties, customer relationship management strategies took shape in the form of new software packages and alliances formed between different corporate giants to retain their target customer base to survive the competition. Some examples can be given as the recent mergers of AT\&T and Cingular, Sears and K-Mart, and talks of acquiring Yahoo! by Microsoft are the steps forward to maintain their niche in the market and expand their customer base.

Services being the largest contributor to the United States' (and many other countries') Gross Domestic Product (GDP), plays a decisive role in directing the development of various tools and technologies in the market [9]. It is an inevitable fact that 'technology' plays a significant role in the course of service development process and needs to be seen as the driving dimension in the service development process [2-4]. The contribution of services had continued to rise (in the vicinity of $\sim 80 \%$ ) in US GDP in last decade or so, as shown in Figure 3.

It is evident from the contribution of services that services cover a wide spectrum of activities responsible for the economic development. Because of their embedded nature, services can sometimes be hard to distinguish from other activities (i.e., mining, agriculture, construction and manufacturing). A more detailed literature on service characteristics can be found in Agrawal, Fitzsimmons and Fitzsimmons [2,7], Several attempts have been made to classify the services, some of the most accepted service classifications in the literature are Schmenner, Bitner, Agnihotri et al. [10-12].

As stated earlier in Section 2 (with Figure 1, and 2) a (service) system exhibits a dynamic hierarchy constituting several sub systems. The dynamic behavior of subsystems directs (large) organizations in strategizing and implementing their CRM activities and vice versa. Based on the specifics of the business, e.g., their strategic motivation and vision; different businesses respond to fluctuations in the market differently. The changes in the market are largely dependent on either the changing perception and needs of customers or a result of the erratic behavior of sub-systems in the system hierarchy. The changing behavior of sub-systems can be explained using varying needs of customers as well, which is a result of introduction of new technologies, products and services in the market. New products and services offered by different organizations drives customers' ever-changing expectations [13] and hence a demand in the market motivating organizations to develop and deliver new services, and hence completing the circle.

Factors such as, market orientation, global strategic growth, technology innovation, management structure, and service blueprints are the driving factors, used in explaining the variations in the service systems development $[2,4]$. The increasingly embedded sub-systems and complexity therein, calls for the implementation of CRM solutions for organizations to assure their (long term) existence in the market. CRM solutions are equally applicable to all segments of the industry, including the service sector and goods sector.

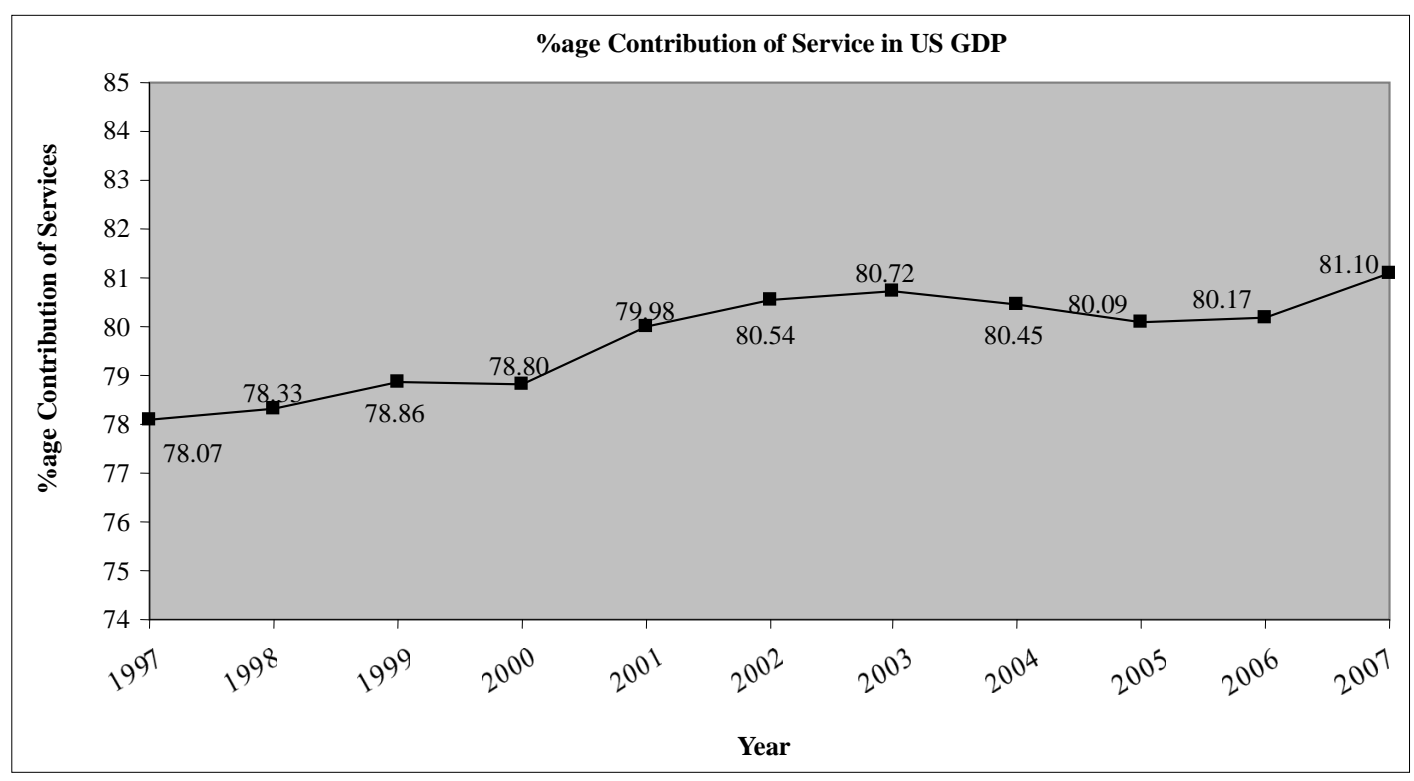

Figure 3. Percentage contribution of service in the US Gross Domestic Product (GDP) source: Bureau of economic analysis 


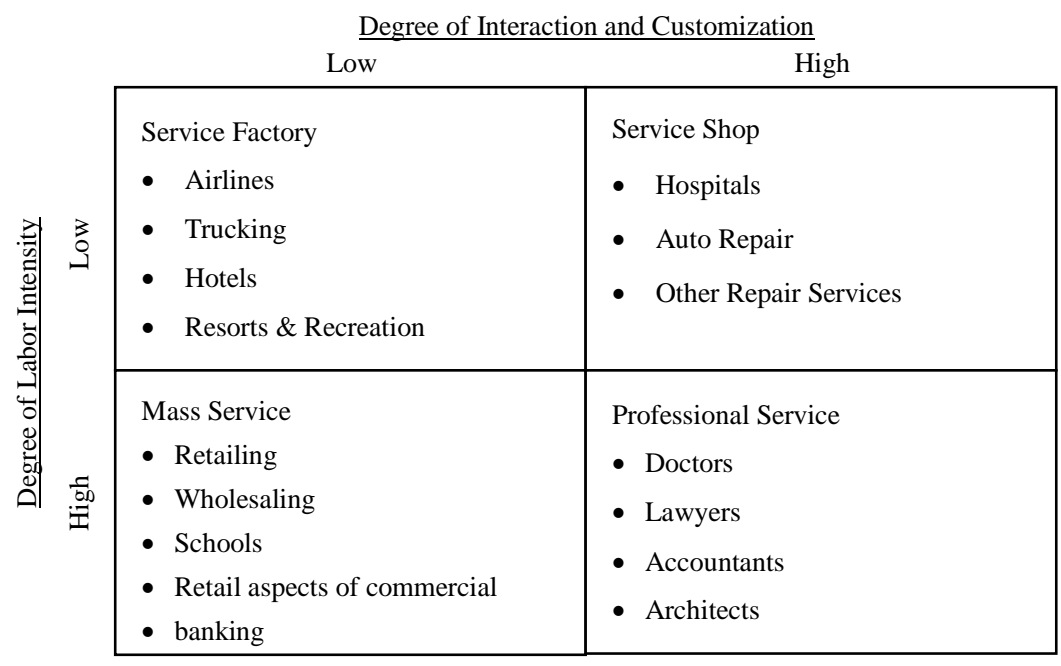

Figure 4. Service-process matrix [10]

\section{The Service Development Process, Technology and CRM}

Service organizations adopt different approaches to develop their services based on the level of technology they choose to use in the course of developing and delivering their services. As discussed in the earlier sections, it is becoming customary for the organizations to implement CRM strategies to stay competitive in the market. Businesses face tough competition from their long existing or low cost international contenders in the market. Although using latest technology and tools, some are able to expand their business networks with uniquely customized services, e.g. OnStar ${ }^{\odot}$ services by General Motors Corporation (GMC). These services added another dimension to already existing global positioning systems (GPS) in the automobile market by providing live customer support to their customers. Even though GM faces great competition in the automobile market, OnStar ${ }^{\complement}$ services gave them an edge in the market to sell not just their products but their customized services as well. To offer such technically intensive services, organizations need to choose the appropriate personnel, infrastructure, hardware and software to be able to implement that specific level of technology to not only developing but also delivering such services.

Among different service businesses (even for the similar kind of services) the level of technical complexity chosen by different organizations to develop and deliver their services causes them to pursue the service development process differently [2]. In a similar fashion, implementing CRM applications in a technology intensive environment would demand a higher level of developmental efforts than a comparatively lower level of technology intensive environment. Reinartz et al. [14] liked CRM process economic performance with the Informa- tion Technology as a critical moderator. Based on the Schmenner's Service-Process matrix (as shown in Figure 4) to classify the services [10], a new model is suggested as the Service-Process-Technology (SPT) matrix (shown in Figure 5) that shall be used in relating the service development process to the level of technology used. The service development process and the level of technology that organizations select to use in developing (and delivering) their services can be visualized and explained using the SPT matrix.

Schmenner used labor intensity (labor to capital ratio), degree of interaction and customization to develop the Service-Process matrix. Using these factors any service organizations can be nominated to one of the four quadrants in the matrix based on the specific characteristics it reflects. As an extension to Service-Process matrix the SPT matrix is proposed with the technology to be used as the $3^{\text {rd }}$ dimension in it. Research studies have established that the level of technology, organizations use to develop their services, affects their service development process immensely [2-4].

The SPT matrix can be used in explaining the relationship between different service systems based on the level of technology they have used to develop their systems. Although only 3 layers are shown in the SPT matrix, it is possible to have a larger number of layers based on the technical complexity and details involved in the analysis. Reinartz et al. [14] stated the need to allocate resources to different tiers of customers based on the economic value (or position in the Service Hierarchy) they have. In an embedded environment, the relationship among different systems can become highly cross linked and ambiguous. Such relationship among (sub) systems makes it essential for the sub (service) systems to keep up with the technology advancements in either master or related sub systems to retain their customer base, which 

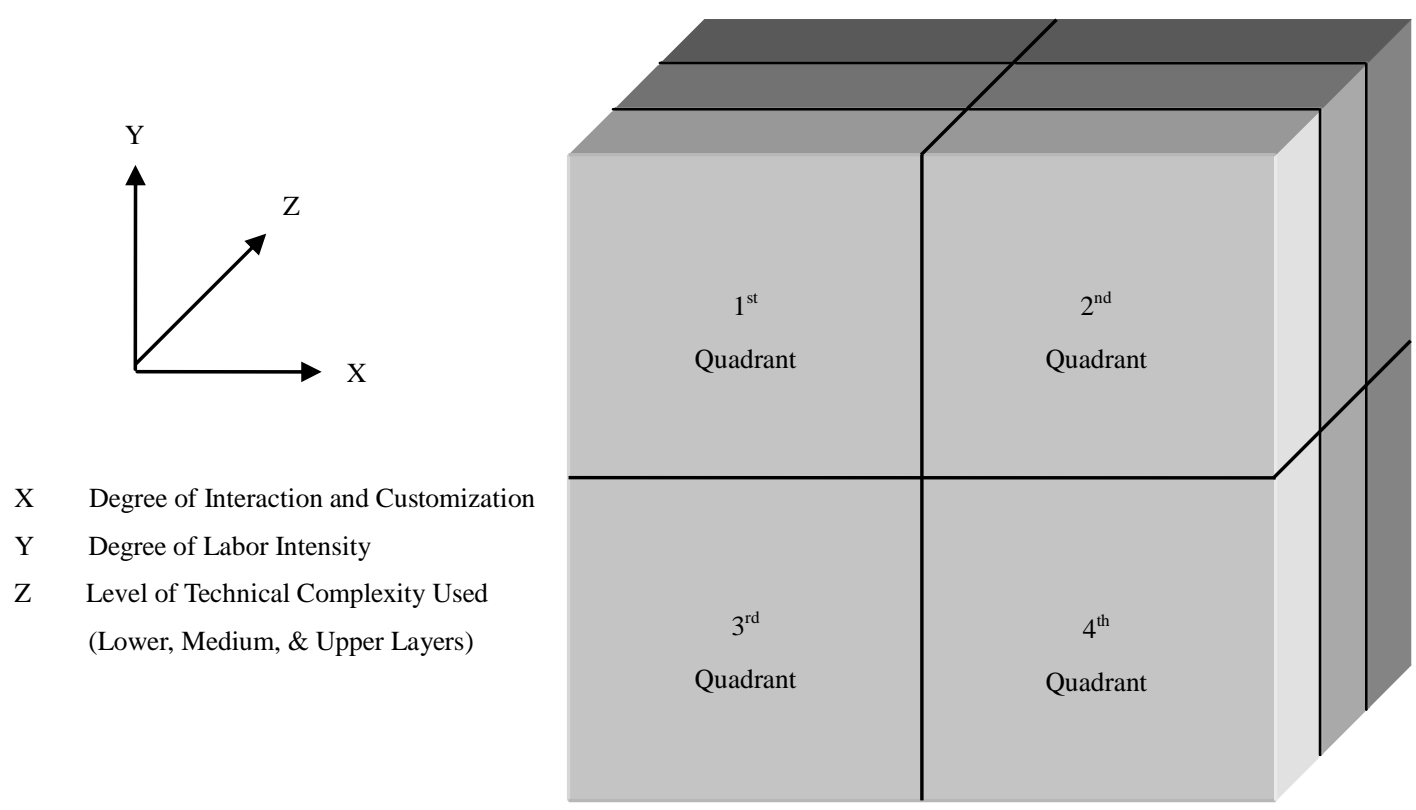

Figure 5. Service-Process-Technology (SPT) matrix

aggressively pursues the technology upgrades available in the market [15].

The implementation of applications such as CRM requires target systems to have some minimum basic technological infrastructure available to them to be able to use CRM applications successfully. As discussed earlier in Section 2, each member in the system hierarchy is capable of affecting other member systems due to their embedded structure and cross relationships. To sustain such minimum requirements, organizations may need to upgrade their existing facilities and hence causing a chaos in the system hierarchy requiring other (attached) subsystems to keep up with them. The relationship between placement of organizations and their subsystems in different 'technology' layers (or level in hierarchy) and the changes/upgrades they need to pursue in order to implement new applications (e.g., CRM) can be explained using SPT matrix like tools. Although, the definition and number of layers in the model may differ for different business types, the matrix features and applicability remains unchanged. As discussed in Section 3, the concept of BPO is playing an important role in the current economic scenario of the United States by giving corporate firms an opportunity to outsource their technical needs to low cost overseas organizations. Because a big part of technology requirements are being outsourced, it is evident that local US companies are being affected greatly and are facing harsh competition in the market to retain their customer base. CRM practices are proven to be helpful in such situations [16]. The organizations outsourcing their operations overseas are implementing and taking advantage of CRM practices as well. With the infrastructural internationalization, organizations with their establishments in the United States are unable to gain any advantage over the organizations that are using overseas resources, in expanding their customer base.

Two organizations situated in different continents, but in the same business, may qualify in different quadrants of Service Process matrix based on the characteristics they reflect in their business models. Research has established that hardware and software (or infrastructural) requirements for different organizations (or quadrants in the Service Process matrix) differ significantly from each other in the course of their service development process. Using the $z$-axis in the SPT matrix (i.e., 'Technology' layer) it is possible to distinguish among different organizations who operate similar businesses but in different quadrants based on the similarities in the technological advancements they pursued over time to implement the CRM like applications. Once the most suitable layer for a system (using the service provider, customer base, technology being implemented, and the quadrants it resides in) is identified, the specific requirements for those organizations can be predicted in terms of the infrastructural updates they would need in the process of implementing an application system such as CRM.

Bitner et al. [17] established (using their Technology Infusion matrix) that technology plays a crucial role in customers' satisfaction in the service encounter process. Bitner used the Technology Infusion matrix as the framework explaining the improvements in the service encounter experience using the available technology effectively. Using the SPT matrix, the change in customers' expectations can be explained subject to an organiza- 
tion's shift from one 'technology' layer to another in terms of the drivers, i.e., customization/flexibility, effective service recovery and spontaneous delight as stated by Bitner et al. [17] in their technology infusion matrix. Also, with the customers' inevitable role in the service delivery process, the organizations' efforts to shift within different technology layers (or quadrants in SPT matrix) can be explained based on the shift in customers' expectations and requirements over time.

\section{Conclusions}

Despite all the attention in services arena, the role of technology in the service development process has not received much attention from researchers, even though the technology development is established to have strong link with the services arena [9]. The need and advent of new applications such as CRM led us to explore the opportunities to study the service organizations using a system based approach and establish the important relationship among different (sub) systems therein.

This paper presented the SPT matrix as one of the solutions that can be used to explain the relationship between different service systems using technology as a common connecting factor among them. Technology being the driving force for (service) organizations to compete in the global markets amid all the intercontinental low cost solutions, it is necessary to have such models available to be able to differentiate among them based on the level of technological advances they wish to pursue over time to stay competitive in the business.

\section{REFERENCES}

[1] L. J. Menor, M. V. Tatikonda, and S. E. Sampson, "New service development: Areas for exploitation and exploration,” Journal of Operations Management, Vol. 20, pp. 135-157, 2002.

[2] G. K. Agrawal, "The development of services: Role and impact of technology in the service development process,” Decision Sciences and Engineering Systems, Rensselaer Polytechnic Institute, Troy, New York, 2006.

[3] G. K. Agrawal and D. Berg, "Technology in the service development process: A missing dimension,” International Journal of Services Technology and Management, Vol. 8, No. 2-3, pp. 107-122, 2007.

[4] G. K. Agrawal and D. Berg, "Role and impact of 'technology' in the service development process: A research study,” International Journal of Services Technology and Management, Vol. 9, No. 2, pp. 103-121, 2008.

[5] I. S. Thukral, "Quality in services through design: An integrated approach,” Decision Sciences and Engineering Systems, Rensselaer Polytechnic Institute, Troy, NY, 1995.

[6] B. Edvardsson and J. Olsson, "Key concepts for new service development," The Service Industries Journal, Vol. 16, No. 2, pp. 140-164, 1996.

[7] J. A. Fitzsimmons and M. J. Fitzsimmons, "Service management: Operations, strategy, information technology," McGraw-Hill Irwin, New York, NY, 2004.

[8] A. Payne and P. Frow, "A strategic framework for customer relationship management,” Journal of Marketing, Vol. 69, pp. 167-176, October 2005.

[9] J. B. Quinn, “Technology in services: Past myths and future challenges,” Technology in Services: Policies for Growth, Trade and Employment. B. R. Guile and J. B. Quinn. Washington, D.C., National Academy Press, pp. 16-46, 1988.

[10] R. W. Schmenner, "How can service businesses survive and prosper?” Sloan Management Review, Vol. 27, No. 3, pp. 21-32, 1986.

[11] M. J. Bitner, "Service and technology: Opportunities and paradoxes,” Managing Service Quality, Vol. 11, No. 6, pp. 375-379, 2001.

[12] S. Agnihothri, N. Sivasubramaniam, and D. Simmons, "Leveraging technology to improve field service," International Journal of Service Industry Management, Vol. 13, No. 1, pp. 47-68, 2002.

[13] R. Adner and D. Levinthal, "Demand heterogeneity and technology evolution: Implications for product and process innovation,” Management Science, Vol. 47, No. 5, pp. 611-628, 2001.

[14] W. Reinartz, M. Krafft, and W. D. Hoyer, "The customer relationship management process: Its measurement and impact on performance,” Journal of Marketing Research, Vol. 41, pp. 293-305, August 2004.

[15] D. A. Norman, “The invisible computer," The MIT Press, Cambridge, MA, 1998.

[16] R. S. Winer, "A Framework for customer relationship management," California Management Review, Vol. 43, No. 4, 2001.

[17] M. J. Bitner, S. W. Brown, and M. L. Meuter, “Technology infusion in service encounters," Journal of the Academy of Marketing Science, Vol. 28, No. 1, pp. 138-149, 2000. 